See Article page 10.

\section{Commentary: Protect the brain: An armamentarium of cerebral-protection strategies should be in the aortic surgeon's toolbox}

\author{
Ankur Bakshi, MD, and Ravi K. Ghanta, MD
}

Aortic arch reconstructions and the use of cerebral perfusion adjuncts are increasingly performed in aneurysm and dissection repairs. ${ }^{1}$ The need for cerebral protection during this period of circulatory arrest was recognized early in the evolution of the field, and techniques for cerebral perfusion were identified as early as 1952 by Drs Cooley and DeBakey. ${ }^{2}$ Antegrade and retrograde cerebral-perfusion strategies allow for longer periods of hypothermic arrest with less hypothermia. ${ }^{3}$ Various strategies have been developed for antegrade cerebral perfusion (ACP), including the use of side-arm grafts or direct cannulation of the axillary artery, innominate artery, or carotid artery.

In this issue of the Journal, Sang and colleagues ${ }^{4}$ present a technique of directly cannulating the innominate artery using a Seldinger technique and pediatric arterial cannula. They use 12- and 14-French pediatric cannulas, which, according to the manufacturer, allow for $1.5-2 \mathrm{~L} / \mathrm{min}$ of flow with acceptable pressures. ${ }^{5}$ The authors present good operative outcomes in 42 patients with $2 \%$ mortality $(n=1$ patient) and, importantly, no clinical strokes. We too preferentially cannulate the innominate artery when the vessel is not dissected or planned to be resected to perform the reconstruction. Preventza and colleagues ${ }^{6}$ examined cannulation of the innominate versus axillary artery and found no

\footnotetext{
From the Michael E. DeBakey Department of Surgery, Baylor College of Medicine, Houston, Tex.

Disclosures: The authors reported no conflicts of interest.

The Journal policy requires editors and reviewers to disclose conflicts of interest and to decline handling or reviewing manuscripts for which they may have a conflict of interest. The editors and reviewers of this article have no conflicts of interest.

Received for publication March 6, 2020; revisions received March 6, 2020; accepted for publication March 8, 2020; available ahead of print April 3, 2020.

Address for reprints: Ravi K. Ghanta, MD, Baylor College of Medicine, One Baylor Plaza, Houston, TX 77030 (E-mail: ravi.ghanta@bcm.edu).

JTCVS Techniques 2020;2:18-9

2666-2507

Copyright (C) 2020 The Authors. Published by Elsevier Inc. on behalf of The American Association for Thoracic Surgery. This is an open access article under the CC BY-NCND license (http://creativecommons.org/licenses/by-nc-nd/4.0/).

https://doi.org/10.1016/j.xjtc.2020.03.014
}

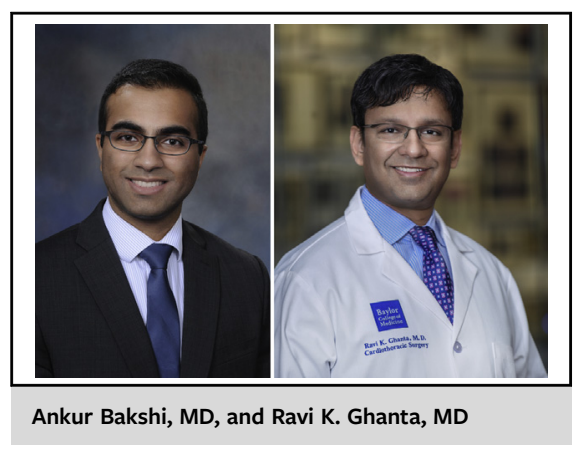

CENTRAL MESSAGE

Direct cannulation of the innominate artery with a pediatric arterial cannula provides another tool in the armamentarium of the aortic surgeon when considering options for antegrade cerebral protection. It can be performed with good operative outcomes.

difference in mortality or neurologic outcomes. As some morbidity and brachial plexus nerve injury is possible with axillary approaches, the innominate artery appears to be the optimal choice for ACP based on current clinical data. $^{7}$ Interestingly, a randomized control trial is currently underway to examine this question, and this question may be conclusively answered. ${ }^{8}$ Another important consideration for all arch reconstructions is the use of unilateral ACP versus bilateral ACP cerebral perfusion, which may be useful for longer circulatory arrest times. ${ }^{9}$

Advantages of the technique described by Sang and colleagues include relative speed and simplicity. During Seldinger cannulation, one must be cognizant of the wire direction and presence of atherosclerosis. One might achieve a similar result with a pediatric angled metal tip cannula; however, this has not been systematically studied as Sang and colleagues have done. Their strategy, however, requires cannulation of the aorta for establishment of cardiopulmonary bypass. Axillary or innominate artery side-arm graft cannulation enables a "one-stop shop" for both cardiopulmonary bypass and ACP.

The authors demonstrate a method that is straightforward and reproducible, and this may help surgeons who are devising cerebral-protection strategies. Complex aortic 
reconstructions require a toolbox of strategies in the surgeon's armamentarium.

\section{References}

1. Hawkins RB, Mehaffey JH, Downs EA, Johnston LE, Yarboro LT, Fonner CE, et al. Regional practice patterns and outcomes of surgery for acute type A aortic dissection. Ann Thorac Surg. 2017;104:1275-81.

2. Debakey ME, Henly WS, Cooley DA, Crawford SE, Morris GC, Beall AC. Aneurysms of the aortic arch: factors influencing operative risk. Surg Clin North Am. 1962;42:1543-54.

3. Okita Y. Neuro-protection in open arch surgery. Ann Cardiothorac Surg. 2018;7: 389-96.

4. Sang SLW, Beute TJ, Timek T. A simple method to establish antegrade cerebral perfusion during hemiarch reconstruction. J Thorac Cardiovasc Surg Tech. 2020;2:10-5.
5. Medtronic. Pediatric Cannula Catalog. 2017. Available at: https://www.medtro nic.com/content/dam/medtronic-com/products/cardiovascular/cannulae/documen ts/pediatric-cannula-catalog.pdf. Accessed March 6, 2020.

6. Preventza O, Price MD, Spiliotopoulos K, Amarasekara HS, Cornwell LD, Omer S et al. In elective arch surgery with circulatory arrest, does the arterial cannulation site really matter? A propensity score analysis of right axillary and innominate artery cannulation. J Thorac Cardiovasc Surg. 2018;155:1953-60.e4.

7. Wong DR, Coselli JC, Palmero L, Bozinovski J, Carter SA, Murariu D, et al. Axillary artery cannulation in surgery for acute or subacute ascending aortic dissections. Ann Thorac Surg. 2010;90:731-7.

8. Garg V, Peterson MD, Chu MWA, Ouzounian M, MacAurthur RGG, Bozinovski J, et al. Axillary versus innominate artery cannulation for antegrade cerebral perfusion in aortic surgery: design of the aortic surgery cerebral protection evaluation (ACE) CardioLink-3 randomised trial. BMJ Open. 2017;7:e014491.

9. Preventza O, Simpson KH, Cooley DA, Cornwell L, Bakaeen FG, Omer S, et al Unilateral versus bilateral cerebral perfusion for acute type A aortic dissection. Ann Thorac Surg. 2014;99:80-7. 